\title{
Transgender women in the female category of sport: is the male performance advantage removed by testosterone suppression?
}

Emma N. Hilton ${ }^{1}$ and Tommy R. Lundberg ${ }^{2,3}$

Affiliations:

1) Faculty of Biology, Medicine and Health, University of Manchester, Manchester, UK.

2) Department of Laboratory Medicine, Division of Clinical Physiology, Karolinska Institutet, Stockholm, Sweden.

3) Unit of Clinical Physiology, Karolinska University Hospital, Stockholm, Sweden.

Correspondence (both authors are available for requests):

Emma N. Hilton, PhD

Faculty of Biology, Medicine and Health

University of Manchester

Oxford Road, Manchester, UK, M13 9PT

E-mail: emma.hilton@manchester.ac.uk

Tommy R. Lundberg, PhD

Karolinska Institutet

Department of Laboratory Medicine/ANA Futura

Division of Clinical Physiology

Alfred Nobles Allé 8B

14152 Huddinge, Sweden

E-mail: tommy.lundberg@ki.se 
Hilton and Lundberg, 2020

\begin{abstract}
Sex dimorphism starts during early embryogenesis and is further manifested in response to hormones during puberty. As this leads to physical divergence that is measurably different between sexes, males enjoy physical performance advantages over females within competitive sport. While this advantage is the underlying basis of the segregation into male and female sporting categories, these sex-based categories do not account for transgender persons who experience incongruence between their biological sex and their experienced gender identity. Accordingly, the International Olympic Committee determined criteria by which a transgender woman may be eligible to compete in the female category, requiring total serum testosterone levels to be suppressed below $10 \mathrm{nmol} / \mathrm{L}$ for at least 12 months prior to and during competition. Whether this regulation removes the male performance advantage has not been collectively scrutinized. Here, we aim to review how differences in biological characteristics between biological males and females affect sporting performance and assess whether evidence exists to support the assumption that testosterone suppression in transgender women removes the male performance advantage. In this review, we report that the performance gap between males and females amounts to $10-50 \%$ depending on sport. The performance gap is more pronounced in sporting activities relying on muscle mass and strength, particularly in the upper body. Longitudinal studies examining the effects of testosterone suppression on muscle mass and strength in transgender women consistently show very modest changes, where the loss of lean body mass, muscle area and strength typically amounts to approximately $5 \%$ after 1 year of treatment. Thus, current evidence shows that the biological advantage enjoyed by transgender women is only minimally reduced when testosterone is suppressed. Sports organizations may therefore be compelled to reassess current policies regarding participation of transgender women in the female category of sport.
\end{abstract}

Key words: androgens, athletic performance, cross-hormone therapy, gender dysphoria, muscle, sex hormones, sporting policies, strength, transgender men, transgender women 
Hilton and Lundberg, 2020

\section{Introduction}

Sporting performance is strongly influenced by a range of physiological factors, including muscle force and power-producing capacity, anthropometric characteristics, cardiovascular capacity and metabolic factors. Many of these physiological factors differ significantly between biological males and females as a result of androgen-directed development of secondary sex characteristics. This confers large sporting performance advantages on biological males over females.

Within directly competing groups (e.g. elite athletes, comparable level of high school athletes), the physiological advantages conferred by biological sex appear, on assessment of performance data, insurmountable. Further, in sports where contact, collision or combat are important for gameplay, widely different physiological attributes may create safety and athlete welfare concerns, necessitating not only segregation of sport into male and female categories, but also, for example, into weight and age classes. Thus, to ensure that both men and women can enjoy sport in terms of fairness, safety and inclusivity, most sports are divided, in the first instance, into male and female categories.

Segregating sports by biological sex does not account for transgender persons who experience incongruence between their biological sex and their experienced gender identity, and whose legal sex may be different to that recorded at birth ${ }^{1,2}$. More specifically, transgender women (observed at birth as biologically male but identifying as women) may, before or after crosshormone treatment, wish to compete in the female category. This has raised concerns about fairness and safety within female competition, and the issue of how to fairly and safely accommodate transgender persons in sport has been subject to much scrutiny ${ }^{1-8}$.

The current International Olympic Committee (IOC) policy ${ }^{9}$ on transgender athletes states that "it is necessary to ensure insofar as possible that trans athletes are not excluded from the opportunity to participate in sporting competition." Yet the policy also states that "the overriding sporting objective is and remains the guarantee of fair competition". As these goals may be seen as conflicting if male performance advantages are carried through to competition in the female category, the $\mathrm{IOC}$ concludes that "restrictions on participation are appropriate to the extent that they are necessary and proportionate to the achievement of that objective."

Accordingly, the IOC determined criteria by which transgender women may be eligible to compete in the female category. These include a solemn declaration that her gender identity is female and the maintenance of total serum testosterone levels below $10 \mathrm{nmol} / \mathrm{L}$ for at least 12 months prior to competing and during competition ${ }^{9}$. Whilst the scientific basis for this testosterone threshold was not openly communicated by the IOC, it is surmised that the IOC believed this testosterone criteria sufficient to mitigate the sporting advantages of biological males over females.

Several studies have examined the effects of testosterone suppression on the changing biology, physiology and performance markers of transgender women. In this review, we aim to assess whether evidence exists to support the assumption that testosterone suppression in transgender women removes these advantages. To achieve this aim, we first review the differences in biological characteristics between biological males and females, and examine 
Hilton and Lundberg, 2020

how those differences affect sporting performance. We then evaluate the studies that have measured elements of performance and physical capacity following testosterone suppression in transgender women, and evaluate whether these findings support the supposition of fairness (i.e. removal of the male performance advantage) as per current sporting guidelines.

\section{The development of male and female bodies}

Humans reproduce sexually via the fusion of two gametes to generate a new individual. Male gametes - sperm - are small, numerous and motile, while female gametes - ova - are large, fewer in number and immobile. In addition to ova production, females also gestate, birth and feed live young. In accordance with these different reproductive roles, males and females have different reproductive anatomies. The physical divergence between reproductive anatomies begins during early embryogenesis, when bipotential gonads are triggered to differentiate into testes or ovaries, the tissues that will produce sperm in males and ova in females, respectively ${ }^{10}$. This fate choice is determined by genetic information inherited at conception, specifically the SRY (sex-determining region $Y$ ) gene harbored by the $Y$ chromosome. Thus, $X Y$ males will activate the SRY gene and trigger testes differentiation, while XX females differentiate ovaries in the absence of SRY activity ${ }^{11,12}$.

Gonad differentiation into testes or ovaries determines, via the specific hormone milieu each generates, downstream events in reproductive anatomy development ${ }^{13}$. Testosterone production in the male testes is required for maturation of the testes itself ${ }^{14}$, development of male-specific internal genitalia (in conjunction with another testes-specific hormone, antiMullerian hormone ${ }^{15}$ ), and development of the bipotential external genitalia field into maletypical structures (via its local conversion to dihydrotestosterone ${ }^{16}$ ). In contrast, female ovaries produce estrogen required, via a network of signals, for ovarian maturation, and low levels of testosterone permits development of female-specific internal and external genitalia 17,18 .

The effects of sex-specific hormones continue after embryonic development of reproductive anatomy is complete ${ }^{19}$. At puberty, under the control of hormones shared between sexes (e.g. growth hormone), both sexes will, for example, gain height and bone density, get oily skin, and experience the onset of sexual desire ${ }^{20}$. In males, production of testosterone in the testes increases dramatically and drives reproductive maturation - testes increase in size and begin to produce sperm, penile size increases, and ejaculation occurs. Under the control of ovarian estrogen, females will initiate egg maturation and begin to ovulate and menstruate, their labia majora will grow, their pelvis will widen in anticipation of childbirth and their breasts grow to prepare for lactation and feeding of young.

\section{The biological basis for sporting performance advantages in males}

Secondary sex characteristics that develop during puberty have evolved under sexual selection pressures to improve reproductive fitness and thus generate anatomical divergence beyond the reproductive system, leading to adult body types that are measurably different between sexes. This phenomenon is known as sex dimorphism. Broadly, and with reference 
Hilton and Lundberg, 2020

to physical performance capacity, males are bigger and stronger than females. It follows that, within competitive sport, males enjoy significant performance advantages over females, predicated on the superior physical capacity developed during puberty in response to testosterone. Indeed, prior to puberty there are inconsequential differences in athletic performance between males and females ${ }^{21}$, and sporting competitions before puberty are often mixed-sex. From puberty onwards, testosterone levels increase 20-fold in males, but remain low in females, resulting in circulating testosterone concentrations at least 15 times higher in males than in females of any age ${ }^{22,23}$. Thus, the biological effects of elevated testosterone, which include changes in muscle mass, strength, anthropometric variables and hemoglobin levels, drive the divergence of athletic performances between males and females 23. It is acknowledged, that this divergence has been compounded historically by a lag in the cultural acceptance of, and financial provision for, females in sport that may have had implications for the rate of improvement in athletic performance in females. Yet, since the 1990s, the difference in performance records between males and females has been relatively stable, suggesting that biological differences explain most of the male advantage, and are insurmountable ${ }^{24}$.

Table 1 outlines physical attributes that are major parameters underpinning the male performance advantage $25,26,35,27-34$. Males have: larger and denser muscle mass, and stiffer connective tissue, with associated capacity to exert greater muscular force more rapidly and efficiently; reduced fat mass, and different distribution of body fat and lean muscle mass, which increases power to weight ratios and upper to lower limb strength in sports where this may be a crucial determinant of success; longer and larger skeletal structure, which creates advantages in sports where levers influence force application, where longer limb/digit length is favorable, and where height, mass and proportions are directly responsible for performance capacity; superior cardiovascular and respiratory function, with larger blood and heart volumes, higher haemoglobin concentration, greater cross-sectional area of the trachea and lower oxygen cost of respiration ${ }^{23,36-38}$.

\section{Sports performance differences between males and females}

\section{An overview of elite adult athletes}

A comparison of adult elite male and female achievements in sporting activities can quantify the extent of the male performance advantage. We searched publicly available sports federation databases and/or tournament/competition records to identify sporting metrics in various events and disciplines, and calculated the performance of males relative to females. Although not an exhaustive list, examples of performance gaps in a range of sports with various durations, physiological performance determinants and force requirements are shown in Figure 1.

The smallest performance gaps were seen in rowing, swimming and running (11-13\%), with low variation across individual events within each of those categories. The performance gap increases to an average of $16 \%$ in track cycling, with higher variation across events (from $9 \%$ in the $4000 \mathrm{~m}$ team pursuit to $24 \%$ in the flying $500 \mathrm{~m}$ time trial). The performance gap is $18 \%$ in jumping events (long jump, high jump, triple jump). Performance differences larger than 
Hilton and Lundberg, 2020

$20 \%$ are generally present when considering sports that include extensive upper body contributions. The gap between fastest recorded tennis serve is $20 \%$, while the gaps between fastest recorded baseball pitches and field hockey drag flicks exceed $50 \%$.

Sports performance relies to some degree on the magnitude, speed and repeatability of force application, and, with respect to the speed of force production (power), vertical jump performance is on average $33 \%$ greater in elite men than women, with differences ranging from $27.8 \%$ for endurance sports to in excess of $40 \%$ for precision and combat sports ${ }^{39}$. Because implement mass differs, direct comparisons are not possible in throwing events in track and field athletics. However, the performance gap is known to be substantial, and throwing represents the widest sex difference in motor performance from an early age ${ }^{40}$. In Olympic javelin throwers, this is manifested in differences in the peak linear velocities of the shoulder, wrist, elbow and hand, all of which are 13-21\% higher for male athletes compared with females ${ }^{41}$.

The increasing performance gap between males and females as upper body strength becomes more critical for performance is likely explained to a large extent by the observation that males have disproportionately greater strength on their upper compared to lower body, while females show the inverse ${ }^{42,43}$. This different distribution of strength compounds the general advantage of increased muscle mass in upper body dominant disciplines. Males also have longer arms than females, which allows greater force production from the arm lever when, for example, throwing a ball, punching or pushing.

\section{Olympic weightlifting}

In Olympic weightlifting, where weight categories differ between males and females, the performance gap is between $31-37 \%$ across the range of competitive body weights between 1998-2020 (Figure 1). It is important to note that at all weight categories below the top/open category, performances are produced within weight categories with an upper limit, where strength can be correlated with "fighting weight", and we have focused our overall analysis on these categories.

To explore strength-mass relationships further, we compared Olympic weightlifting data between equivalent weight categories which, to some extent, limit athlete height, to examine the hypothesis that male performance advantage may be largely (or even wholly) mediated by increased height and lever-derived advantages (Table 2). Between 1998 and 2018, a $69 \mathrm{~kg}$ category was common to both males and females, with the male record holder $(69 \mathrm{~kg}, 1.68$ $\mathrm{m}$ ) lifting a combined weight $30.1 \%$ heavier than the female record holder $(69 \mathrm{~kg}, 1.64 \mathrm{~m})$. Weight category changes in 2019 removed the common $69 \mathrm{~kg}$ category and created a common $55 \mathrm{~kg}$ category. The current male record holder $(55 \mathrm{~kg}, 1.52 \mathrm{~m}$ ) lifts $29.5 \%$ heavier than the female record holder $(55 \mathrm{~kg}, 1.52 \mathrm{~m})$. These comparisons demonstrate that males are approximately $30 \%$ stronger than females of equivalent stature and mass. However, importantly, male weightlifting performance gaps increase with increasing bodyweight, particularly in the absence of weight limits. In the top/open weight category of Olympic weightlifting, there is no competitive pressure to restrict bodyweight and, in the absence of weight (and associated height) limits, maximum male lifting strength exceeds female lifting strength by nearly $40 \%$. This is further manifested in powerlifting, where the male record 
Hilton and Lundberg, 2020

(total of squat, bench press and deadlift) is $65 \%$ higher than the female record in the open weight category of the World Open Classic Records. Further analysis of Olympic weightlifting data shows that the $55 \mathrm{~kg}$ male record holder is $6.5 \%$ stronger than the $69 \mathrm{~kg}$ female record holder (294 kg vs $276 \mathrm{~kg}$ ), and that the $69 \mathrm{~kg}$ male record is 3.2\% higher than the record held by a $108 \mathrm{~kg}$ woman (359 kg vs $348 \mathrm{~kg}$ ). This Olympic weightlifting analysis reveals key differences between male and female strength capacity. It shows that, even after adjustment for mass, biological males are significantly stronger (30\%) than females, and that females who are $60 \%$ heavier than males do not overcome these strength deficits.

\section{Perspectives on elite athlete performance differences}

We have quantified the performance gap between adult elite males and adult elite females across various disciplines. The translation of these advantages, assessed as the performance difference between the very best males and very best females, are significant when extended and applied to larger populations. In running events, for example, where the male-female gap is approximately $11 \%$, it follows that many thousands of males are faster than the very best females. For example, about 10000 males have run faster than the current Olympic female champion (World Athletics, personal communication, July 2019). This has also been described elsewhere ${ }^{44,45}$, and illustrates the true effect of an $11 \%$ typical difference on population comparisons between males and females. This is further apparent upon examination of selected junior male records, which surpass adult elite female performances by the age of 1415 years (Table 3 ), demonstrating superior male athletic performance over elite females within a few years of the onset of puberty.

These data overwhelmingly confirm that testosterone-driven puberty, as the driving force of development of male secondary sex characteristics, underpins sporting advantages that are so large no female could reasonably hope to succeed without sex segregation in most sporting competition. To ensure, in light of these analyses, that female athletes can be included in sporting competition in a fair and safe manner, most sports have a female category whose purpose is the protection of both fairness and, in some sports, safety/welfare of athletes who do not benefit from the physiological changes induced by male levels of testosterone.

\section{Performance differences in non-elite individuals}

The male performance advantages described above in athletic cohorts are similar in magnitude in untrained people. Even when expressed relative to fat-free weight, $\mathrm{VO}_{2 \max }$ is 12 to $15 \%$ higher in males than in females ${ }^{46}$. Records of lower-limb muscle strength reveal a $50 \%$ difference in peak torque between males and females consistently across the lifespan ${ }^{28}$. Hubal et al. ${ }^{47}$ tested 342 women and 243 men for isometric (maximal voluntary contraction) and dynamic strength (one-repetition maximum; 1RM) of the elbow flexor muscles and performed magnetic resonance imaging (MRI) of the biceps brachii to determine crosssectional area. The males had $57 \%$ greater muscle size, $109 \%$ greater isometric strength, and $89 \%$ greater $1 \mathrm{RM}$ strength than age-matched females. This reinforces the finding in athletic cohorts that sex differences in muscle size and strength are more pronounced in the upper body. 
Recently, sexual dimorphism in arm force and power was investigated in a punch motion ${ }^{48}$ in non-trained individuals. The power produced during a punch was $162 \%$ greater in males than in females, and the least powerful man produced more power than the most powerful woman. This highlights that sex differences in parameters such as mass, strength and speed may combine to produce even larger sex differences in sport-specific actions, which often are a product of how various physical capacities combine. For example, power production is the product of force and velocity, and momentum is defined as mass $x$ velocity. The momentum and kinetic energy that can be transferred to another object, such as during a tackle or punch in collision and combat sports, are therefore dictated by: the mass; force to accelerate that mass, and; resultant velocity attained by that mass. As there is a male advantage for each of these factors, the net result is likely synergistic in a sport-specific action, such as a tackle or a throw, that widely surpasses the sum of individual magnitudes of advantage in isolated fitness variables. Indeed, already at 17 years of age, the average male throws a ball further than $99 \%$ of 17 -year-old females ${ }^{49}$, despite no single variable (arm length, muscle mass etc.) reaching this numerical advantage. Similarly, punch power is $162 \%$ greater in men than women ${ }^{48}$ even though no single parameter that produces punching actions achieves this magnitude of difference.

\section{Is the male performance advantage lost when testosterone is suppressed in transgender women?}

The current IOC criteria for inclusion of transgender women in female sports categories requires testosterone suppression below $10 \mathrm{nmol} / \mathrm{L}$ for 12 months prior to and during competition. Given the IOC's stated position that the "overriding sporting objective is and remains the guarantee of fair competition" ${ }^{9}$, it is reasonable to assume that the rationale for this requirement is that it reduces or eliminates the male performance advantages described previously, thus permitting fair and safe competition. To determine whether this medical intervention is sufficient to mitigate the male performance advantage, which we describe above, we performed a systematic search of the scientific literature addressing the anthropometric and muscle characteristics of transgender women. Search terms and filtering of peer-reviewed data is given in Supplementary Table S1.

\section{Anthropometrics}

Given its importance for the general health of the transgender population, there are multiple studies of bone health, and reviews of these data. To summarise, transgender women often have low baseline (pre-intervention) bone mineral density (BMD), attributed to low levels of physical activity, especially weight-bearing exercise, and low Vitamin D levels ${ }^{50,51}$. However, transgender women generally maintain bone mass over the course of at least 24 months of testosterone suppression. There may even be small but significant increases in BMD at the lumbar spine 52,53 . Some included studies present data pertaining to maintained BMD in transgender women after many years of testosterone suppression ${ }^{54}$. One such study ${ }^{54}$ concluded that "BMD is preserved over a median of 12.5 years". In support, no increase in fracture rates was observed over 12 months of testosterone suppression ${ }^{52}$. Current advice, including that from the International Society for Clinical Densitometry, is that transgender women, in the absence of other risk factors, do not require monitoring of $B M D{ }^{50,55}$. 
Hilton and Lundberg, 2020

Given the maintenance of BMD and the lack of a plausible biological mechanism by which testosterone suppression might affect skeletal measurements such as bone length and hip width, we conclude that height and skeletal parameters remain unaltered in transgender women, and that sporting advantage conferred by skeletal size and bone density would be retained despite testosterone reductions compliant with the IOC's current guidelines.

\section{Muscle and strength metrics}

As discussed earlier, muscle mass and strength are key parameters underpinning male performance advantages. Strength differences range between $30 \%$ and $100 \%$, depending upon the cohort studied and the task used to assess strength. Thus, given the important contribution made by strength to performance, we sought to examine studies that have assessed strength changes after prolonged testosterone reduction. Studies retrieved in our literature search covered both longitudinal and cross-sectional analyses. Given the superior power of the former study type, we will focus on these.

The pioneer work by Gooren and colleagues, published in part in $1999{ }^{56}$ and in full in $2004{ }^{57}$, reported the effects of 1 and 3 years of testosterone suppression and estrogen supplementation in 19 transgender women (age 18-37 years). After the first year of therapy, testosterone levels were reduced to $1 \mathrm{nmol} / \mathrm{L}$, well within typical female reference ranges, and remained low throughout the study course. As determined by MRI, thigh muscle area had decreased by $9 \%$ from baseline measurement. After 3 years, thigh muscle area had decreased by a further $3 \%$ from baseline measurement (total loss of $12 \%$ over three years of treatment). However, when compared with the baseline measurement of thigh muscle area in transgender men (who are born female and experience female puberty), transgender women retained significantly higher thigh muscle size. The final thigh muscle area, after three years of testosterone suppression, was $13 \%$ larger in transwomen than in the transmen at baseline $(p<0.05)$. The authors concluded that testosterone suppression in transgender women does not reverse muscle size to female levels.

Since Gooren and Bunck ${ }^{57}, 11$ longitudinal studies ${ }^{51,58,67,59-66}$ have examined the effects of testosterone suppression on lean body mass or muscle size in transgender women. The collective evidence from these studies suggests that 1 year of testosterone suppression to female-typical reference levels results in a modest loss of lean body mass or muscle size (Table 4). No study has reported muscle loss exceeding the $12 \%$ found by Gooren and Bunck after 3 years of therapy. Notably, studies have found very consistent changes in lean body mass after 1 year of treatment, where the change has always been between -3 to $-5 \%$ on average, with slightly greater reductions in the arm compared with the leg region ${ }^{63}$.

Thus, given the large baseline differences in muscle mass between males and females (Table 1; approximately $40 \%$ ), the reduction achieved by 12 months of testosterone suppression can reasonably be concluded to be small relative to the initial superior mass. We therefore conclude that the muscle mass advantage males possess over females, and potentially the performance implications thereof, are not removed by 12 months of testosterone suppression. 
To provide more detailed information on not only gross body composition but also thigh muscle volume and contractile density, Wiik et al. ${ }^{66}$ recently carried out a comprehensive battery of MRI and computed tomography (CT) examinations before and after 12 months of successful testosterone suppression and estrogen supplementation in 11 transgender women. Thigh volume (both anterior and posterior thigh) and quadriceps cross-sectional area decreased $4-5 \%$ after the 12-month period, supporting previous results of modest effects of testosterone suppression on muscle mass (see Table 4). The more novel measure of radiological attenuation of the quadriceps muscle, a valid proxy of contractile density 68,69 , showed no significant change in transgender women after 12 months of treatment, whereas the parallel group of transgender men demonstrated a $6 \%$ increase in contractile density with testosterone supplementation. This suggest that the force producing capacity per unit of muscle cross-sectional area (i.e. specific force) is intact in the transgender women after 1 year of treatment.

As indicated earlier (e.g. Table 1), the difference in muscle strength between males and females is often more pronounced than the difference in muscle mass. Unfortunately, few studies have examined the effects of testosterone suppression on muscle strength or other proxies of performance in transgender individuals. The first such study was published online approximately one year prior to the release of the current IOC policy on inclusion of transgender women in female sports categories. In this study, van Caenegem et al. ${ }^{51}$ reported that hand-grip strength was reduced from baseline measurements by $7 \%$ and $9 \%$ after 1 and 2 years, respectively, of cross-hormone treatment in transgender women.

In a recent multicenter study ${ }^{65}$, examination of 249 transgender women revealed a decrease of $4 \%$ in grip strength after 1 year of cross-hormone treatment, with no variation between different testosterone level, age or BMI tertiles (all transgender women studied were within female reference ranges for testosterone). Despite this modest reduction in strength, transgender women retained a $17 \%$ grip strength advantage over transgender men (observed at birth as biologically female but identifying as men) measured at baseline.

Although grip strength provides an excellent proxy measurement for general strength in a broad population, specific assessment within different muscle groups is more valuable in a sports-specific framework. Wiik et al., ${ }^{66}$ having determined that thigh muscle mass reduces only modestly, and that no significant changes in contractile density occur with 12 months of testosterone suppression, provided, for the first time, data for isokinetic strength measurements of both knee extension and knee flexion. They reported that muscle strength was similar after 12 months of testosterone suppression compared to baseline. As a result, transgender women remained about $50 \%$ stronger than a reference group of females and the group of transgender men at baseline.

These longitudinal data comprise a clear pattern of very modest to negligible changes in muscle mass and strength in transgender women suppressing testosterone for at least 12 months. Muscle mass and strength are key physical parameters that constitute a significant, if not majority, portion of the male performance advantage in sport, and thus our analysis strongly suggests that the reduction in testosterone levels required by many sports federation transgender policies is insufficient to remove or reduce the male advantage by any meaningful degree. 
Hilton and Lundberg, 2020

Although less powerful than longitudinal studies, we identified one major cross-sectional study that measured muscle mass and strength in transgender women. In this study ${ }^{70}, 23$ transgender women and 46 healthy age- and height-matched control males were compared. The transgender women were recruited at least 3 years after sex reassignment surgery, and the mean duration of cross-hormone treatment was 8 years. The results showed that transgender women had $17 \%$ less lean mass and $25 \%$ lower peak quadriceps muscle strength than the control males. This cross-sectional comparison suggests that a mean treatment duration of 8 years substantially reduces muscle mass and strength in transgender women. However, the typical gap in lean mass and strength between males and females at baseline measurements (Table 1 ) typically exceeds the differences reported by Lapauw et al. and implies a retained physical advantage even after 8 years of testosterone suppression.

\section{Endurance performance and cardiovascular parameters}

No controlled longitudinal study has explored the effects of testosterone suppression on endurance-based performance. Sex differences in endurance performance are generally smaller than for events relying more on muscle mass and strength, and may even disappear at ultra-endurance distances ${ }^{71}$. Using an age grading model designed to normalize times for masters/veteran categories, Harper ${ }^{72}$ analyzed self-reported race times for eight transgender women runners of various age categories who had, over a 7 year period, competed in subelite middle distance races within both the male and female categories. The age-graded scores for these eight runners were the same in both categories, suggesting that the cross-hormone treatment resulted in reduced running performance by approximately the size of the typical male advantage. However, factors affecting performances in the interim, including training and injury, were uncontrolled for over periods of years.

Circulating hemoglobin levels are androgen-dependent and typically reported as $12 \%$ higher in males compared with females ${ }^{23}$. As hemoglobin levels appear to decrease by $11-14 \%$ with cross-hormone therapy in transgender women ${ }^{57,66}$, and indeed significantly in athletes with Differences of Sex Development (DSD) where those athletes are sensitive to testosterone ${ }^{45}$, oxygen-carrying capacity is most likely reduced with concomitant performance penalty. Moreover, the typical increase in body fat noted in transgender women ${ }^{73,74}$ may also be a disadvantage for sporting activities where body weight (or fat distribution) presents a marginal disadvantage. Whether these changes reduce performance results in transgender women endurance athletes to an extent that the male advantage is removed remains unknown.

\section{Discussion}

The data presented here demonstrates that the male physical performance advantage over females, attributed to superior anthropometric and muscle mass/strength parameters achieved at puberty, is not removed by the current regimen of testosterone suppression permitting participation of transgender women in female sports categories. Rather, it appears that the male performance advantage is largely retained by transgender women and thus remains substantial. This raises concerns about the overriding sporting objective of fair and 
Hilton and Lundberg, 2020

safe competition that sporting governing bodies have often attempted to balance against inclusion of transgender women in female sport ${ }^{9}$. Whilst available evidence is strong and convincing to suggest that strength, skeletal- and muscle-mass derived advantages will largely remain, certain elements do warrant further research for application to highly-trained and elite contexts.

\section{Athletic status}

The current body of evidence pertaining to physiological changes observed in transgender women after at least 12 months of testosterone suppression has been obtained from cohorts of transgender women who are measured as having regular or even low activity ${ }^{75}$. The extent of musculoskeletal changes in athletic transgender women, particularly those engaged in intensive strength, weight-bearing and/or resistance training, is unknown. One possible hypothesis is that strength training throughout testosterone suppression might minimise even the modest changes observed in non-athletic cohorts. However, it is also possible that transgender women with greater trained muscle mass at baseline may experience larger decreases in mass and strength than non-athletic transgender women. This remains a gap in current data.

\section{The focus on muscle mass and strength}

We acknowledge that changes in strength measurements are not always correlated in magnitude to changes in muscle mass; muscle mass (or total mass) is not the only contributor to strength ${ }^{76}$. Indeed, the importance of the nervous system, e.g. muscle agonist activation (recruitment and firing frequency) and antagonist co-activation, for muscle strength must be acknowledged ${ }^{77}$. In addition, factors such as fiber types, biomechanical levers, pennation angle, fascicle length and tendon/extracellular matrix composition may all influence the ability to develop muscular force ${ }^{78}$. While there is currently limited to no information on how these factors are influenced by testosterone suppression, impact seems to be minute, given the modest changes noted in muscle strength during cross-hormone treatment.

It is possible that estrogen replacement may affect the sensitivity of muscle to anabolic signaling and have a protective effect on muscle mass ${ }^{79}$ explaining, in part, the modest change in muscle mass with testosterone suppression and accompanying cross-hormone treatment. Indeed, this is supported by research conducted on estrogen replacement therapy in other targeted populations ${ }^{80,81}$ and in several different animal models, including mice after gonadectomy ${ }^{82}$ and ovariectomy ${ }^{83}$.

\section{Testosterone limits}

The appropriate testosterone limit for participation of transgender women in the female category has been a matter of debate recently, where sports federations such as World Athletics and World Rugby recently lowered the eligibility criterion of free circulating testosterone to $<5 \mathrm{nmol} / \mathrm{L}$. This was likely based, at least in part, on a thorough review by Handelsman et al. ${ }^{23}$, where the authors concluded that, given the nonoverlapping, bimodal distribution of circulating testosterone between males and females, and making an allowance 
Hilton and Lundberg, 2020

for females with mild hyperandrogenism (e.g. with polycystic ovary syndrome), the appropriate testosterone limit should be 5 rather than $10 \mathrm{nmol} / \mathrm{L}$.

From the longitudinal muscle mass/strength studies summarised here, however, it is apparent that most therapeutical interventions to date result in almost complete suppression of testosterone levels (Table 4). Thus, with regard to transgender women athletes, we question whether current circulating testosterone level cut-off can be a meaningful decisive factor, when in fact not even suppression down to around $1 \mathrm{nmol} / \mathrm{L}$ removes the anthropometric and muscle mass/strength physical advantage in any significant way.

In terms of the duration of testosterone suppression, one could argue that if one year of treatment is not sufficient to remove the male advantage, then perhaps extending the time frame of suppression could be a viable option. However, based on the studies reviewed in here, evidence is lacking that this would diminish the male advantage to a justifiable degree. On the contrary, it appears that the net loss of lean mass and grip strength is not substantially decreased at year 2 or 3 of cross-hormone treatment (Table 4). This indicates that a plateau or a new steady state is reached within the first year of treatment, a phenomenon also noted in transgender men, where the increase in muscle mass seems to stabilise between the first and the second year of testosterone treatment ${ }^{84}$.

\section{Perspectives}

We have shown that under testosterone suppression regimes commonly required by sports federations to permit inclusion of transgender women in female sports categories, evidence for loss of the male performance advantage, established by testosterone at puberty and translating in elite athletes to a $10-50 \%$ performance advantage, is lacking. Rather, the data shows that the physical advantage enjoyed by biological males over females is only minimally reduced when testosterone is suppressed as per current and historical policies. Furthermore, the reductions observed in muscle mass, size, and strength are very small compared to the baseline differences between males and females in these variables. These data significantly undermine the intent of these policies, particularly given the stated prioritization of fairness as an overriding objective (as per the IOC policy). If those policies are purported to promote fairness, inclusion and safety of biologically female athletes, this review compels sporting organizations to reassess their policies regarding inclusion of transgender women.

From a medical-ethical point of view, it may be questioned as to whether a requirement to lower testosterone below a certain level to ensure sporting participation can be justified at all. If the advantage persists to a large degree, as evidence suggests, then a stated objective of targeting a certain testosterone level to be eligible will not achieve its objective and may drive medical practice that an individual may not want or require, without achieving its intended benefit.

The research conducted so far has studied untrained transgender women. Thus, while this research is important to understand the isolated effects of testosterone suppression, it is still uncertain how transgender women athletes, perhaps undergoing advanced training regimens during the therapy, would respond. It is also important to recognize that performance in most 
sports may be influenced by factors outside muscle mass and strength. Thus, there is certainly a need for more focused research on this topic, including more comprehensive performance tests in transgender athletes. Moreover, since inclusiveness and fairness must be balanced against athlete safety, proper risk assessment should be conducted within respective sport.

If transgender women remain, either with restriction or in full, excluded from the female category of sport, the important question is whether or not this exclusion, or conditional exclusion, is necessary and proportionate to the goal of ensuring fair, safe and meaningful competition. Regardless of what the future will bring in terms of revised transgender policies, it is obvious that different sports differ vastly from each other in terms of physiological determinants of success, which then create safety considerations and may alter the importance or magnitude of performance advantages. Thus, one could certainly argue against universal transgender guidelines in sport and instead propose that each individual sports federation should evaluate their own conditions for inclusivity, fairness and safety.

\section{Conflict of Interest}

The authors declare no conflict of interest. 
Hilton and Lundberg, 2020

\section{References}

1 Genel M. Transgender Athletes: How Can They Be Accommodated? Curr Sports Med Rep. 2017;16(1):12-13.

2 Coggon J, Hammond N, Holm S. Transsexuals in sport - fairness and freedom, regulation and law. Sport Ethics Philos. 2008;2(1):4-17.

3 Pitsiladis Y, Harper J, Betancurt JO et al. Beyond Fairness. Curr Sports Med Rep. 2016;15(6):386-388.

4 Reeser JC. Gender identity and sport: Is the playing field level? Br J Sports Med. 2005;39(10):695-699.

5 Ingram BJ, Thomas CL. Transgender Policy in Sport, A Review of Current Policy and Commentary of the Challenges of Policy Creation. Curr Sports Med Rep. 2019;18(6):239-247.

6 Harper J, Martinez-Patino MJ, Pigozzi F, Pitsiladis Y. Implications of a Third Gender for Elite Sports. Curr Sports Med Rep. 2018;17(2):42-44.

7 Singh B, Singh K. The Hermeneutics of Participation of Transgender Athletes in Sports Intensifying Third Force. Phys Cult Sport Stud Res. 2011;52(1):44-48.

8 Bianchi A. Transgender women in sport. J Philos Sport. 2017;44(2):229-242.

9 Harper J, Hirschberg AL, Jose M et al. IOC Consensus Meeting on Sex Reassignment and Hyperandrogenism. 2015 Available at: https://stillmed.olympic.org/Documents/Commissions_PDFfiles/Medical_commission /2015-11_ioc_consensus_meeting_on_sex_reassignment_and_hyperandrogenismen.pdf.

10 Carré GA, Greenfield A. The Gonadal Supporting Cell Lineage and Mammalian Sex Determination: The Differentiation of Sertoli and Granulosa Cells. Results Probl Cell Differ. 2016;58:47-66.

11 Sekido R, Lovell-Badge R. Sex determination and SRY: down to a wink and a nudge? Trends Genet. 2009;25(1):19-29.

12 Kashimada K, Koopman P. Sry: Sry: the master switch in mammalian sex determination. Development. 2010;137(23):3921-3930.

13 Sobel V, Zhu YS, Imperato-McGinley J. Fetal hormones and sexual differentiation. Obstet Gynecol Clin North Am. 2004;31(4):837-xi.

14 Heinrich A, DeFalco T. Essential roles of interstitial cells in testicular development and function [published online ahead of print, 2019 Aug 24]. Andrology.

15 Behringer RR. The in vivo roles of müllerian-inhibiting substance. Curr Top Dev Biol. 1994;29:171-187.

16 Wilson JD, Griffin JE, Leshin M, George FW. Role of gonadal hormones in development of the sexual phenotypes. Hum Genet. 1981;58(1):78-84.

17 Sajjad Y. Development of the genital ducts and external genitalia in the early human embryo. J Obstet Gynaecol Res. 2010;36(5):929-937.

18 Koopman P. The Curious World of Gonadal Development in Mammals. Curr Top Dev Biol. 2016;116:537-545.

19 Graber JA, Metz A. Tanner Stages. In: Bornstein MH. The SAGE Encyclopedia of Lifespan Human Development. 2018 doi:10.4135/9781506307633.n814.

20 Bordini B, Rosenfield RL. Normal pubertal development: Part I: The endocrine basis of puberty. Pediatr Rev. 2011;32(6):223-229.

21 Tønnessen E, Svendsen IS, Olsen IC, Guttormsen A, Haugen T. Performance 
Hilton and Lundberg, 2020

development in adolescent track and field athletes according to age, sex and sport discipline. PLoS One. 2015;10(6):e0129014.

22 Bae YJ, Zeidler R, Baber R et al. Reference intervals of nine steroid hormones over the life-span analyzed by LC-MS/MS: Effect of age, gender, puberty, and oral contraceptives. J Steroid Biochem Mol Biol. 2019;193:105409.

23 Handelsman DJ, Hirschberg AL, Bermon S. Circulating Testosterone as the Hormonal Basis of Sex Differences in Athletic Performance. Endocr Rev. 2018;39(5):803-829.

24 Sandbakk $\varnothing$, Solli GS, Holmberg HC. Sex differences in world-record performance: The influence of sport discipline and competition duration. Int J Sports Physiol Perform. 2018;13(1):2-8.

25 Lee DH, Keum N, Hu FB et al. Development and validation of anthropometric prediction equations for lean body mass, fat mass and percent fat in adults using the National Health and Nutrition Examination Survey (NHANES) 1999-2006. Br J Nutr. 2017;118(10):858-866.

26 Janssen I, Heymsfield SB, Wang ZM, Ross R. Skeletal muscle mass and distribution in 468 men and women aged 18-88 yr. J Appl Physiol. 2000;89(1):81-88.

27 Bohannon RW, Wang YC, Yen SC, Grogan KA. Handgrip strength: A comparison of values obtained from the NHANES and NIH Toolbox studies. Am J Occup Ther. 2019;73(2):7302205080p1-7302205080p9.

28 Neder JA, Nery LE, Shinzato GT, Andrade MS, Peres C, Silva AC. Reference values for concentric knee isokinetic strength and power in nonathletic men and women from 20 to 80 years old. J Orthop Sports Phys Ther. 1999;29(2):116-126.

29 Jantz LM, Jantz RL. Secular change in long bone length and proportion in the United States, 1800-1970. Am J Phys Anthropol. 1999;110(1):57-67.

30 Brinckmann $P$, Hoefert $H$, Jongen HT. Sex differences in the skeletal geometry of the human pelvis and hip joint. J Biomech. 1981;14(6):427-430.

31 Lepley AS, Joseph MF, Daigle NR et al. Sex differences in mechanical properties of the achilles tendon: Longitudinal response to repetitive loading exercise. J Strength Cond Res. 2018;32(11):3070-3079.

32 Pate RR, Kriska A. Physiological Basis of the Sex Difference in Cardiorespiratory Endurance. Sport Med An Int J Appl Med Sci Sport Exerc. 1984;1(2):87-89.

33 Astrand PO, Cuddy TE, Saltin B, Stenberg J. Cardiac Output during Submaximal and Maximal Work. J Appl Physiol. 1964;19:268-274.

34 Best SA, Okada Y, Galbreath MM et al. Age and sex differences in muscle sympathetic nerve activity in relation to haemodynamics, blood volume and left ventricular size. Exp Physiol. 2014;99(6):839-848.

35 Tong E, Murphy WG, Kinsella A et al. Capillary and venous haemoglobin levels in blood donors: a 42-month study of 36258 paired samples. Vox Sang. 2010;98(4):547-553.

36 Haizlip KM, Harrison BC, Leinwand LA. Sex-based differences in skeletal muscle kinetics and fiber-type composition. Physiology (Bethesda). 2015;30(1):30-39.

37 Dominelli PB, Molgat-Seon Y, Sheel AW. Sex Differences in the Pulmonary System Influence the Integrative Response to Exercise. Exerc Sport Sci Rev. 2019;47(3):142-150.

38 Wingate S. Cardiovascular anatomy and physiology in the female. Crit Care Nurs Clin North Am. 1997;9(4):447-452.

39 Haugen T, Breitschädel F, Wiig H, Seiler S. Countermovement jump height in national team athletes of various sports: a framework for practitioners and scientists. Int J Sports Physiol Perform. 2020. (accessed 4 May2020 from Researchgate). 
Hilton and Lundberg, 2020

40 Thomas JR, French KE. Gender differences across age in motor performance a metaanalysis. Psychol Bull. 1985;98(2):260-282.

41 Antti M, Komi P V., Korjus T, Navarro E, Gregor RJ. Body Segment Contributions to Javelin Throwing during Final Thrust Phases. J Appl Biomech. 1994;10:166-177.

42 Lassek WD, Gaulin SJC. Costs and benefits of fat-free muscle mass in men: relationship to mating success, dietary requirements, and native immunity. Evol Hum Behav. 2009;20(5):322-328.

43 Stoll T, Huber E, Seifert B, Michel BA, Stucki G. Maximal isometric muscle strength: normative values and gender-specific relation to age. Clin Rheumatol. 2000;19(2):105113.

44 Coleman DL. Sex in sport. Law Contemp Probl. 2017;:63-126.

45 CAS 2018/O/5794 Mokgadi Caster Semenya v. International Association of Athletics Federation. Available at: https://www.tascas.org/fileadmin/user_upload/CAS_Award_-_redacted_-_Semenya_ASA_IAAF.pdf.

46 Sparling PB. A meta-analysis of studies comparing maximal oxygen uptake in men and women. Res Q Exerc Sport. 1980;51(3):542-552.

47 Hubal MJ, Gordish-dressman H, Thompson PD et al. Muscle Size and Strength Gain after Unilateral Resistance Training. Med Sci Sport Exerc. 2005;37(6):964-972.

48 Morris JS, Link J, Martin JC, Carrier DR. Sexual dimorphism in human arm power and force: implications for sexual selection on fighting ability. J Exp Biol. 2020;223(Pt 2):jeb212365.

49 Thomas JR, Thomas KT. Development of gender differences in physical activity. Quest. 1988;40(3):219-229.

50 Wiepjes CM, de Jongh RT, de Blok CJM et al. Bone Safety During the First Ten Years of Gender-Affirming Hormonal Treatment in Transwomen and Transmen. J Bone Miner Res. 2019;34(3):447-454.

51 Van Caenegem E, Wierckx K, Taes Y et al. Preservation of volumetric bone density and geometry in trans women during cross-sex hormonal therapy: a prospective observational study. Osteoporos Int. 2015;26(1):35-47.

52 Singh-Ospina N, Maraka S, Rodriguez-Gutierrez R et al. Rodriguez-Gutierrez R, et al. Effect of Sex Steroids on the Bone Health of Transgender Individuals: A Systematic Review and Meta-Analysis. J Clin Endocrinol Metab. 2017;102(11):3904-3913.

53 Fighera TM, Ziegelmann PK, Rasia da Silva T, Spritzer PM. Bone Mass Effects of CrossSex Hormone Therapy in Transgender People: Updated Systematic Review and MetaAnalysis. J Endocr Soc. 2019;3(5):943-964.

54 Ruetsche AG, Kneubuehl R, Birkhaeuser MH, Lippuner K. Cortical and trabecular bone mineral density in transsexuals after long-term cross-sex hormonal treatment: a crosssectional study. Osteoporos Int. 2005;16(7):791-798.

55 Rosen HN, Hamnvik OPR, Jaisamrarn U et al. Bone Densitometry in Transgender and Gender Non-Conforming (TGNC) Individuals: 2019 ISCD Official Position.J Clin Densitom. 2019;22(4):544-553.

56 Elbers JM, Asscheman H, Seidell JC, Gooren LJ. Effects of sex steroid hormones on regional fat depots as assessed by magnetic resonance imaging in transsexuals. Am J Physiol. 1999;276(2):E317-25.

57 Gooren LJG, Bunck MCM. Transsexuals and competitive sports. Eur J Endocrinol. 2004;151(4):425-9.

58 Haraldsen IR, Haug E, Falch J, Egeland T, Opjordsmoen S. Cross-sex pattern of bone 
Hilton and Lundberg, 2020

mineral density in early onset gender identity disorder. Horm Behav. 2007;52(3):334343.

59 Mueller A, Zollver H, Kronawitter D et al. Body composition and bone mineral density in male-to-female transsexuals during cross-sex hormone therapy using gonadotrophin-releasing hormone agonist. Exp Clin Endocrinol Diabetes. 2011;119(2):95-100.

60 Wierckx K, Van Caenegem E, Schreiner T et al. Cross-sex hormone therapy in trans persons is safe and effective at short-time follow-up: results from the European network for the investigation of gender incongruence. J Sex Med. 2014;11(8):19992011.

61 Gava G, Cerpolini S, Martelli V, Battista G, Seracchioli R, Meriggiola MC. Cyproterone acetate vs leuprolide acetate in combination with transdermal oestradiol in transwomen: a comparison of safety and effectiveness. Clin Endocrinol (Oxf). 2016;85(2):239-246.

62 Auer MK, Ebert T, Pietzner M et al. Effects of Sex Hormone Treatment on the Metabolic Syndrome in Transgender Individuals: Focus on Metabolic Cytokines. J Clin Endocrinol Metab. 2018;103(2):790-802.

63 Klaver M, De Blok CJM, Wiepjes CM et al. Changes in regional body fat, lean body mass and body shape in trans persons using cross-sex hormonal therapy: Results from a multicenter prospective study. Eur J Endocrinol. 2018;178(2):163-171.

64 Fighera TM, da Silva E, Lindenau JDR, Spritzer PM. Impact of cross-sex hormone therapy on bone mineral density and body composition in transwomen. Clin Endocrinol (Oxf). 2018;88(6):856-862.

65 Scharff M, Wiepjes CM, Klaver M, Schreiner T, T'Sjoen G, Heijer M Den. Change in grip strength in trans people and its association with lean body mass and bone density. Endocr Connect. 2019;8(7):1020-1028.

66 Wiik A, Lundberg TR, Rullman E et al. Muscle Strength, Size, and Composition Following 12 Months of Gender-affirming Treatment in Transgender Individuals. J Clin Endocrinol Metab. 2020;105(3):dgz247.

67 Tack LJW, Craen M, Lapauw B et al. Proandrogenic and Antiandrogenic Progestins in Transgender Youth: Differential Effects on Body Composition and Bone Metabolism. J Clin Endocrinol Metab. 2018;103(6):2147-2156.

68 Aubrey J, Esfandiari N, Baracos VE et al. Measurement of skeletal muscle radiation attenuation and basis of its biological variation. Acta Physiol (Oxf). 2014;210(3):489497.

69 Rasch A, Byström AH, Dalen N, Berg HE. Reduced muscle radiological density, crosssectional area, and strength of major hip and knee muscles in 22 patients with hip osteoarthritis. Acta Orthop. 2007;78(4):505-510.

70 Lapauw B, Taes $Y$, Simoens $S$ et al. Body composition, volumetric and areal bone parameters in male-to-female transsexual persons. Bone. 2008;43(6):1016-1021.

71 Speechly DP, Taylor SR, Rogers GG. Differences in ultra-endurance exercise in performance-matched male and female runners. Med Sci Sports Exerc. 1996;28(3):359365.

72 Harper J. Race Times for Transgender Athletes. J Sport Cult Identities. 2015;6(1):1-9.

73 T'Sjoen G, Arcelus J, Gooren L, Klink DT, Tangpricha V. Endocrinology of transgender medicine. Endocr. Rev. 2018;40(1):97-117.

74 Klaver M, Dekker MJHJ, de Mutsert R, Twisk JWR, den Heijer M. Cross-sex hormone 
therapy in transgender persons affects total body weight, body fat and lean body mass: a meta-analysis. Andrologia. 2017;49(5):10.1111/and.12660.

75 Muchicko MM, Lepp A, Barkley JE. Peer victimization, social support and leisure-time physical activity in transgender and cisgender individuals. Leis Loisir. 2014;(3-4):295308.

76 Balshaw TG, Massey GJ, Maden-Wilkinson TM et al. Changes in agonist neural drive, hypertrophy and pre-training strength all contribute to the individual strength gains after resistance training. Eur J Appl Physiol. 2017;117(4):631-640.

77 Balshaw TG, Massey GJ, Maden-Wilkinson TM, Lanza MB, Folland JP. Neural adaptations after 4 years vs 12 weeks of resistance training vs untrained. Scand J Med Sci Sports. 2019;29(3):348-359.

78 Maden-Wilkinson TM, Balshaw TG, Massey GJ, Folland JP. What makes long-term resistance-trained individuals so strong? A comparison of skeletal muscle morphology, architecture, and joint mechanics. J Appl Physiol. 2020;128(4):1000-1011.

79 Chidi-Ogbolu N, Baar K. Effect of Estrogen on Musculoskeletal Performance and Injury Risk. Front Physiol. 2019;9:1834.

80 Sørensen MB, Rosenfalck AM, Højgaard L, Ottesen B. Obesity and sarcopenia after menopause are reversed by sex hormone replacement therapy. Obes Res. 2001;9(10):622-626.

81 Greising SM, Baltgalvis KA, Lowe DA, Warren GL. Hormone therapy and skeletal muscle strength: a meta-analysis. J Gerontol A Biol Sci Med Sci. 2009;64(10):1071-1081.

82 Svensson J, Movérare-Skrtic S, Windahl S, Swanson C, Sjögren K. Stimulation of both estrogen and androgen receptors maintains skeletal muscle mass in gonadectomized male mice but mainly via different pathways. J Mol Endocrinol. 2010;45(1):45-57.

83 Kitajima Y, Ono Y. Estrogens maintain skeletal muscle and satellite cell functions. $J$ Endocrinol. 2016;229(3):267-275.

84 Elbers JMH, Asscheman H, Seidell JC, Megens JAJ, Gooren LJG. Long-Term Testosterone Administration Increases Visceral Fat in Female to Male Transsexuals ${ }^{1}$. J Clin Endocrinol Metab. 1997;82(7):2044-2047.

\section{Figure legends}

Figure 1. The male performance advantage over females across various sporting disciplines. The female level is set to $100 \%$. In sport events with multiple disciplines, the male value has been averaged across disciplines, and the error bars represent the range of the advantage. The metrics were compiled from publicly available sports federation databases and/or tournament/competition records. 


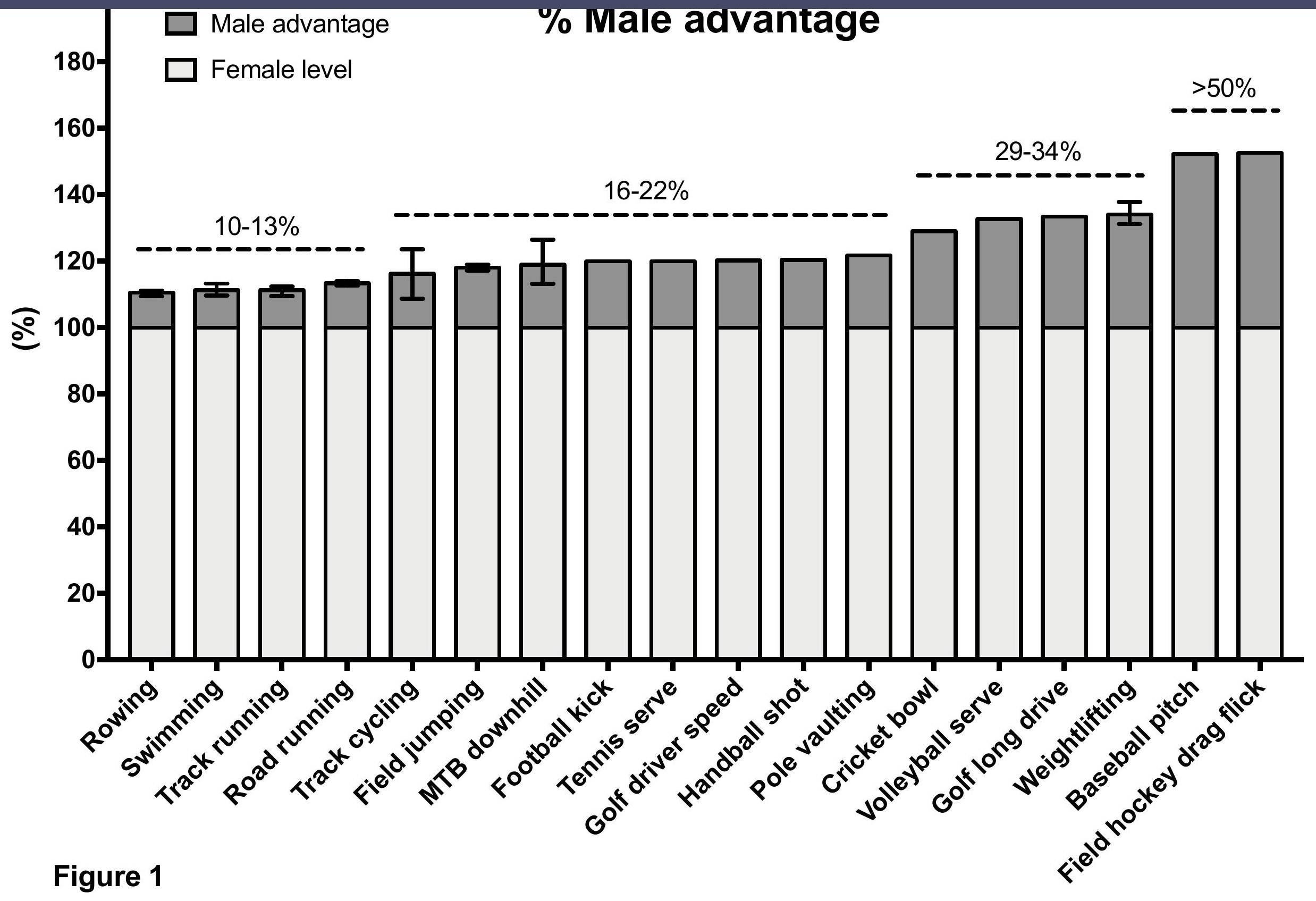


Table 1. Selected physical difference between untrained/moderately trained males and females. Female levels are set as the reference value.

\begin{tabular}{|c|c|c|}
\hline Variable & Magnitude of sex difference & References \\
\hline \multicolumn{3}{|l|}{ Body composition } \\
\hline $\begin{array}{l}\text { Lean body mass } \\
\text { Fat\% }\end{array}$ & $\begin{array}{l}45 \% \\
-30 \%\end{array}$ & Lee et al. (25) \\
\hline \multicolumn{3}{|l|}{ Muscle mass } \\
\hline $\begin{array}{l}\text { Lower body } \\
\text { Upper body }\end{array}$ & $\begin{array}{l}33 \% \\
40 \%\end{array}$ & Janssen et al. (26) \\
\hline \multicolumn{3}{|l|}{ Muscle strength } \\
\hline $\begin{array}{l}\text { Grip strength } \\
\text { Knee extension peak torque }\end{array}$ & $\begin{array}{l}57 \% \\
54 \%\end{array}$ & $\begin{array}{l}\text { Bohannon et al. (27) } \\
\text { Neder et al. (28) }\end{array}$ \\
\hline \multicolumn{3}{|l|}{ Anthropometry and bone geometry } \\
\hline $\begin{array}{l}\text { Femur length } \\
\text { Humerus length } \\
\text { Radius length } \\
\text { Pelvic width relative to pelvis height }\end{array}$ & $\begin{array}{l}9.4 \% \\
12.0 \% \\
14.6 \% \\
-6.1 \%\end{array}$ & $\begin{array}{l}\text { Jantz et al. (29) } \\
\text { Brinckmann et al. (30) }\end{array}$ \\
\hline \multicolumn{3}{|l|}{ Tendon properties } \\
\hline $\begin{array}{l}\text { Force } \\
\text { Stiffness }\end{array}$ & $\begin{array}{l}83 \% \\
41 \% \\
\end{array}$ & Lepley et al. (31) \\
\hline \multicolumn{3}{|l|}{ VO2 max } \\
\hline $\begin{array}{l}\text { Absolute values } \\
\text { Relative values }\end{array}$ & $\begin{array}{l}50 \% \\
25 \% \\
\end{array}$ & Pate et al. (32) \\
\hline \multicolumn{3}{|l|}{ Respiratory function } \\
\hline Pulmonary ventilation (maximal) & $48 \%$ & Åstrand et al. (33) \\
\hline \multicolumn{3}{|l|}{ Cardiovascular function } \\
\hline $\begin{array}{l}\text { Left ventricular mass } \\
\text { Cardiac output (rest) } \\
\text { Cardiac output (maximal) } \\
\text { Stroke volume (rest) } \\
\text { Stroke volume (maximal) } \\
\text { Hemoglobin concentration }\end{array}$ & $\begin{array}{l}31 \% \\
22 \% \\
30 \% \\
43 \% \\
34 \% \\
11 \%\end{array}$ & $\begin{array}{l}\text { Åstrand et al. (33) } \\
\text { Best et al. (34) } \\
\text { Tong et al. (35) }\end{array}$ \\
\hline
\end{tabular}


Table 2. Olympic weightlifting data between equivalent male-female and top/open weight categories.

\begin{tabular}{|l|c|c|c|c|c|c|}
\hline & Sex & $\begin{array}{c}\text { Weight } \\
\mathbf{( k g})\end{array}$ & $\begin{array}{c}\text { Height } \\
(\mathbf{m})\end{array}$ & $\begin{array}{c}\text { Combined } \\
\text { record (kg) }\end{array}$ & $\begin{array}{c}\text { Strength to } \\
\text { weight ratio }\end{array}$ & $\begin{array}{c}\text { Relative } \\
\text { performance }\end{array}$ \\
\hline 2019 record in the 55 kg weight-limited category \\
\hline Liao Qiuyun & $\mathrm{F}$ & 55 & 1.52 & 227 & 4.13 & \\
\hline Om Yun-chol & $\mathrm{M}$ & 55 & 1.52 & 294 & 5.35 & $29.5 \%$ \\
\hline $\mathbf{1 9 9 8 - 2 0 1 8}$ record in the $\mathbf{6 9} \mathbf{~ k g}$ weight-limited category \\
\hline Oxsana Slivenko & $\mathrm{F}$ & 69 & 1.64 & 276 & 4.00 & \\
\hline Liao Hui & $\mathrm{M}$ & 69 & 1.68 & 359 & 5.20 & $30.1 \%$ \\
\hline Comparative performances for top/open categories (all time heaviest combined lifts) \\
\hline Tatiana Kashirina & $\mathrm{F}$ & 108 & 1.77 & 348 & 3.22 & \\
\hline Lasha Talakhadze & $\mathrm{M}$ & 168 & 1.97 & 484 & 2.88 & $39.1 \%$ \\
\hline
\end{tabular}

$\mathrm{F}=$ Female, $\mathrm{M}=$ Male 
Table 3. Selected junior male records in comparison with adult elite female records.

\begin{tabular}{|l|c|c|}
\hline Event & Schoolboy male record & Elite female (adult) record \\
\hline $100 \mathrm{~m}$ & 10.20 (age 15) & 10.49 \\
\hline $800 \mathrm{~m}$ & $1: 51.23$ (age 14) & $1: 53.28$ \\
\hline $1500 \mathrm{~m}$ & $3: 48.37$ (age 14) & $3: 50.07$ \\
\hline Long jump & $7.85 \mathrm{~m}$ (age 15) & $7.52 \mathrm{~m}$ \\
\hline Discus throw & $77.68 \mathrm{~m}$ (age 15) & $76.80 \mathrm{~m}$ \\
\hline
\end{tabular}

$\mathrm{m}=$ meters

Time format: minutes:seconds.hundredths of a second 
Table 4. Longitudinal studies of muscle and strength changes in adult transgender women undergoing cross-sex hormone therapy. Studies reporting measures of lean mass, muscle volume, muscle area or strength are included. Muscle/strength data is calculated in reference to baseline cohort data and, where reported, reference female (or transgender men before treatment) cohort data.

\begin{tabular}{|c|c|c|c|c|c|}
\hline Study & Participants (age) & Therapy & $\begin{array}{l}\text { Confirmed serum } \\
\text { testosterone levels }\end{array}$ & Muscle/strength data & $\begin{array}{l}\text { Comparison with } \\
\text { reference females }\end{array}$ \\
\hline Gooren and Bunck $2004^{57}$ & $\mathrm{~N}=19 \mathrm{TW} 26 \pm 6 \mathrm{yr}$ & $\begin{array}{l}\text { T suppression + E } \\
\text { supplementation }\end{array}$ & $\leq 1 \mathrm{nmol} / \mathrm{L}$ at 1 and $3 \mathrm{yr}$ & $\begin{array}{l}\text { Thigh area } \\
1 \mathrm{yr}-9 \% / 3 \mathrm{yr}-12 \%\end{array}$ & $\begin{array}{l}\text { Thigh area } \\
1 \text { yr } 16 \% \text { / } 3 \text { yr } 13 \%\end{array}$ \\
\hline Haraldsen et al. $2007^{58}$ & $\mathrm{~N}=12 \mathrm{TW} 29 \pm 8 \mathrm{yr}$ & E supplementation & $<10 \mathrm{nmol} / \mathrm{L}$ at $3 \mathrm{mo}$ and $1 \mathrm{yr}$ & $\begin{array}{l}\text { LBM } \\
3 \text { mo / } 1 \text { yr - small changes, } \\
\text { unclear magnitude }\end{array}$ & \\
\hline Mueller et al. $2011^{59}$ & $\begin{array}{l}\mathrm{N}=84 \text { TW } 36 \pm 11 \\
\mathrm{yr}\end{array}$ & $\begin{array}{l}\text { T suppression + E } \\
\text { supplementation }\end{array}$ & $\leq 1 \mathrm{nmol} / \mathrm{L}$ at 1 and $2 \mathrm{yr}$ & $\begin{array}{l}\text { LBM } \\
1 \mathrm{yr}-4 \% / 2 \mathrm{yr}-7 \%\end{array}$ & \\
\hline Wierckx et al. $2014^{60}$ & $\begin{array}{l}\mathrm{N}=53 \text { TW } 31 \pm 14 \\
\mathrm{yr}\end{array}$ & $\begin{array}{l}\text { T suppression + E } \\
\text { supplementation }\end{array}$ & $<10 \mathrm{nmol} / \mathrm{L}$ at $1 \mathrm{yr}$ & $\begin{array}{l}\text { LBM } \\
1 \mathrm{yr}-5 \%\end{array}$ & $\begin{array}{l}\text { LBM } \\
1 \mathrm{yr} 39 \%\end{array}$ \\
\hline $\begin{array}{l}\text { Van Caenegem et al. } 2015 \\
51\end{array}$ & $\begin{array}{l}\mathrm{N}=49 \mathrm{TW} \\
33 \pm 14 \mathrm{yr}\end{array}$ & $\begin{array}{l}\text { T suppression + E } \\
\text { supplementation }\end{array}$ & $\leq 1 \mathrm{nmol} / \mathrm{L}$ at 1 and $2 \mathrm{yr}$ & $\begin{array}{l}\text { LBM } \\
1 \text { yr -4\% / } 2 \text { yr -0.5\% } \\
\text { Grip strength } \\
1 \text { yr -7\% / } 2 \text { yr -9\% } \\
\text { Calf area } \\
1 \text { yr -2\% / } 2 \text { yr -4\% } \\
\text { Forearm area } \\
1 \text { yr -8\% / } 2 \text { yr -4\% }\end{array}$ & \\
\hline Gava et al. $2016^{61}$ & $\begin{array}{l}\mathrm{N}=40 \mathrm{TW} \\
31 \pm 10 \mathrm{yr}\end{array}$ & $\begin{array}{l}\text { T suppression }+\mathrm{E} \\
\text { supplementation }\end{array}$ & $\begin{array}{l}<5 \mathrm{nmol} / \mathrm{L} \text { at } 6 \mathrm{mo} \text { and } \leq 1 \\
\mathrm{nmol} / \mathrm{L} \text { at } 1 \mathrm{yr}\end{array}$ & $\begin{array}{l}\text { LBM } \\
1 \mathrm{yr}-2 \%\end{array}$ & \\
\hline Auer et al. $2018^{62}$ & $\begin{array}{l}\mathrm{N}=72 \mathrm{TW} \\
35 \pm 1(\mathrm{SE}) \mathrm{yr}\end{array}$ & $\begin{array}{l}\text { T suppression + E } \\
\text { supplementation }\end{array}$ & $<5 \mathrm{nmol} / \mathrm{L}$ at $1 \mathrm{yr}$ & $\begin{array}{l}\text { LBM } \\
1 \mathrm{yr}-3 \%\end{array}$ & $\begin{array}{l}\text { LBM } \\
1 \text { yr } 27 \%\end{array}$ \\
\hline Klaver et al. $2018^{63}$ & $\begin{array}{l}\mathrm{N}=179 \mathrm{TW} \\
29 \text { (range } 18-66)\end{array}$ & $\begin{array}{l}\text { T suppression }+\mathrm{E} \\
\text { supplementation }\end{array}$ & $\leq 1 \mathrm{nmol} / \mathrm{L}$ at $1 \mathrm{yr}$ & $\begin{array}{l}\text { LBM } 1 \text { yr } \\
\text { total -3\% } \\
\text { arm region -6\% } \\
\text { trunk region -2\% } \\
\text { android region 0\% } \\
\text { gynoid region -3\% } \\
\text { leg region }-4 \%\end{array}$ & $\begin{array}{l}\text { LBM } 1 \text { yr } \\
\text { total } 18 \% \\
\text { arm region } 28 \% \\
\text { leg region } 19 \%\end{array}$ \\
\hline Fighera et al. $2018^{64}$ & $\begin{array}{l}\mathrm{N}=46 \mathrm{TW} \\
34 \pm 10\end{array}$ & $\begin{array}{l}\text { E supplementation with } \\
\text { or without T suppression }\end{array}$ & $\begin{array}{l}<5 \mathrm{nmol} / \mathrm{L} \text { at } 3 \mathrm{mo} \\
\leq 1 \mathrm{nmol} / \mathrm{L} \text { at } 31 \mathrm{mo}\end{array}$ & $\begin{array}{l}\text { ALM } \\
31 \text { mo }-4 \% \text { from the } 3 \text { mo visit }\end{array}$ & \\
\hline
\end{tabular}




\begin{tabular}{|c|c|c|c|c|c|}
\hline Scharff et al. $2019^{65}$ & $\begin{array}{l}\mathrm{N}=249 \text { TW } \\
28 \text { (inter quartile } \\
\text { range } 23-40 \text { ) }\end{array}$ & $\begin{array}{l}\text { T suppression + E } \\
\text { supplementation }\end{array}$ & $\leq 1 \mathrm{nmol} / \mathrm{L}$ at $1 \mathrm{yr}$ & $\begin{array}{l}\text { Grip strength } \\
1 \mathrm{yr}-4 \%\end{array}$ & $\begin{array}{l}\text { Grip strength } \\
1 \text { yr } 21 \%\end{array}$ \\
\hline Wiik et al. $2019^{66}$ & $\begin{array}{l}\mathrm{N}=11 \mathrm{TW} \\
27 \pm 4\end{array}$ & $\begin{array}{l}\text { T suppression }+\mathrm{E} \\
\text { supplementation }\end{array}$ & $\leq 1 \mathrm{nmol} / \mathrm{L}$ at $4 \mathrm{mo}$ and at $1 \mathrm{yr}$ & $\begin{array}{l}\text { Thigh volume } \\
1 \mathrm{yr}-5 \% \\
\text { Quad area } \\
1 \mathrm{yr}-4 \% \\
\text { Knee extension strength } \\
1 \mathrm{yr} 2 \% \\
\text { Knee flexion strength } \\
1 \mathrm{yr} \%\end{array}$ & $\begin{array}{l}\text { Thigh volume } \\
1 \mathrm{yr} 33 \% \\
\text { Quad area } \\
26 \% \\
\text { Knee extension strength } \\
41 \% \\
\text { Knee flexion strength } \\
33 \%\end{array}$ \\
\hline
\end{tabular}

$\mathrm{N}=$ number of participants. $\mathrm{TW}$ - transgender women. $\mathrm{yr}$ - year. mo - month. $\mathrm{T}$ - testosterone. $\mathrm{E}-$ estrogen. \pm standard deviation (unless otherwise indicated in text). LBM - lean body mass. ALM - appendicular lean mass. Tack et al. ${ }^{67}$ was not included in the table since some of the participants had not undergone full puberty at treatment initiation. 